\title{
Variasi tekanan dalam proses metalurgi serbuk dan pengaruhnya pada modulus elastisitas bahan komposit Al-SiC
}

\author{
Mochamad Zainuri, ${ }^{1, *}$ Yoni Moniada, ${ }^{1}$ dan Darminto ${ }^{1}$ \\ ${ }^{1}$ Jurusan Fisika - FMIPA , Institut Teknologi Sepuluh Nopember, Kampus ITS Sukolilo, Surabaya 60111
}

\begin{abstract}
Intisari
Preparasi bahan komposit bermatriks logam $\mathrm{Al}$ dengan penguat $\mathrm{SiC}$ telah dilakukan dengan menerapkan gaya kompaksi sebesar 15, 20 dan $25 \mathrm{kN}$ dalam proses metalurgi serbuk. Kompaksi dengan tekanan yang lebih besar daripada kekuatan luluh Al menyebabkan penurunan kualitas ikatan permukaan, sebagai akibat terjebaknya gas dan bahan pelumas yang digunakan dalam proses fabrikasi. Kualitas terbaik dari ikatan antar permukaan antara bahan matriks dan penguat dicapai oleh sampel yang disiapkan dengan gaya kompresi sebesar $15 \mathrm{kN}$, dengan nilai modulus Young yang terletak di antara batas upper dan lower bound. Analisis selanjutnya dengan model partikel penguat menggunakan geometri tabung dan kubus untuk komposit isotropik dapat memprediksi nilai modulus elastisitasnya yang sesuai dengan hasil eksperimen. $\quad$ (c) 2005 Jurusan Fisika FMIPA ITS
\end{abstract}

KATA KUNCI:

\section{PENDAHULUAN}

Fabrikasi bahan komposit bermatriks logam (metalmatrix composites/MMC)) melalui teknik metalurgi serbuk (powder metallurgy) memiliki beberapa keunggulan dibandingkan dengan cara metalurgi cair (liquid metallurgy). Suhu yang dipergunakan dalam proses metalurgi serbuk dapat lebih rendah, yaitu di bawah titik leleh bahan. Sedangkan pada teknik metalurgi cair diperlukan suhu tinggi hingga mencapai titik leleh bahan komponennya [1]. Teknik pembentukan logam dengan metode metalurgi serbuk pada dasarnya adalah memproses paduan dua atau lebih serbuk logam menjadi bahan komposit, dengan sifat mekanik yang berbeda dari sifat masing-masing penyusunnya. Secara umum langkah proses yang harus dilalui antara lain pengaturan komposisi (compounding), pencampuran serbuk (mixing), penekanan (compacting), dan pemanasan (sintering) [1-3]. Salah satu langkah proses yang akan dikaji dan dilakukan variasi dalam penelitian ini adalah pengaruh kompaksi pada kualitas komposit yang dibentuk atas dasar kinerja mekaniknya. Dalam proses kompaksi, terjadi ikatan permukaan antar partikel serbuk dengan timbulnya gaya adesi-kohesi melalui tiga cara utama [1, 4]: (1) penguncian (interlocking) antar permukaan, (2) gaya elektrostatik, dan (3) gaya Van der Waals. Dari ketiga gaya tersebut, peneliti mencoba memprediksi ikatan permukaan berdasarkan gaya Vander Waals, di mana gaya tersebut dapat mengakomodasi tiga kemungkinan model geometri partikel ser-

*E-MAIL: zainuri@physics.its.ac.id buk $[4,5]$ :

1. Model bola-bola, terjadi jika besar gaya tekan yang diberikan berada di bawah harga kekuatan luluh (yield strength) dari matriks maupun penguat (filler/reinforcer).

2. Model bola-bidang, terjadi jika besar gaya tekan yang diberikan berada di antara kekuatan luluh matriks dan penguat.

3. Model bidang-bidang, terjadi jika besar gaya tekan yang diberikan berada di atas kekuatan luluh matriks maupun penguat.

Masing-masing model di atas memiliki bentuk persamaan gaya sebagai berikut [4]:

$$
\begin{aligned}
\text { bola-bola } & F_{\nu}=\frac{A}{12 H^{2}} \frac{D_{P 1}}{D_{P 2}} \\
\text { bola bidang } & F_{\nu}=\frac{A D_{P}}{12 H^{2}} \\
\text { bidang-bidang } & F_{\nu}=\frac{\hbar \bar{\omega}}{8 \pi_{2} H^{12}},
\end{aligned}
$$

dengan $A$ adalah konstanta Hamaker, $D_{P 1}$ dan $D_{P 2}$ diameter partikel, $H$ jarak antar permukaan partikel dan $\hbar$ konstanta Lifshits . Untuk model partikel berbentuk bola-bola, jarak antar permukaan dapat didekati dengan $r-\left(D_{P 1}+D_{P 2}\right) / 2$ dan untuk bentuk bola-bidang didekati dengan $r-D_{P} / 2$, dimana $r$ merupakan jarak pusatpusat bola atau jarak antara pusat bola dan permukaan bidang. Konstanta Hameker untuk dua material yang berbeda dinyatakan dengan :

$$
A_{12}=\sqrt{A_{11} A_{22}}
$$




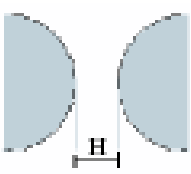

(a)

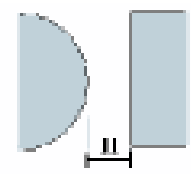

(t)

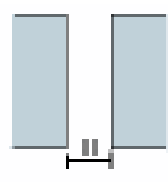

Gambar 1: Model butiran setelah penekanan (a) bola-bola, (b) bola-bidang, (c) bidang-bidang. $\mathrm{H}$ jarak antar permukaan partikel.

dengan $A_{11}$ dan $A_{22}$ merupakan konstanta Hameker untuk bahan 1 dan bahan 2 . Keterkaitan antara konstanta Hameker dan konstanta Lifshits - Van der Waals secara makrokopis dinyatakan dengan :

$$
A=\frac{3}{4 \pi} \hbar \bar{\omega}
$$

Nilai konstanta Hameker tergantung jenis materialnya, di udara terbuka konstanta untuk : air $=4,4 \times 10^{-20} \mathrm{~J}$, hidrogen $=(4-6) \times 10^{-20} \mathrm{~J}$, senyawa oksida dan halida $=(6-$ 15) $\times 10^{-20} \mathrm{~J}$, serta logam $=(15-50) \times 10^{-20} \mathrm{~J}[4]$.

Selanjutnya, nilai modulus Young dari komposit didekati dengan persamaan Hal Pin Tsi [6], untuk model penguat tabung dan kubus sebagai berikut. Dalam model ini partikel penguat dianggap berbentuk tabung dengan perbandingan tinggi dan diameter $\leq 1$. Persamaan dalam model tabung diungkapkan dalam bentuk :

$$
E_{c}=\frac{3}{8} E_{L}+\frac{5}{8} E_{T}
$$

dengan

$$
\begin{aligned}
& E_{L}= \frac{E_{m}\left[1+\left(\frac{2 d}{l}\right) \eta_{L} V f\right]}{1-\eta_{L} V_{f}} \\
& E_{T}= \frac{E_{m}\left[1+2 \eta_{T} V f\right]}{1-\eta_{T} V_{f}} \\
& \eta_{L}= \frac{\frac{E_{f}}{E_{m}}-1}{\frac{E_{f}}{E_{m}}+\frac{2 l}{d}} \\
& \eta_{T}= \frac{E_{f}}{E_{m}}-1 \\
& \frac{E_{f}}{E_{m}}+2
\end{aligned}
$$

dan $d$ adalah diameter tabung, $L$ tinggi tabung, $E_{f}$ modulus elastisitas penguat, $E_{m}$ modulus elastisitas matriks dan $V_{f}$ fraksi volume penguat. Lebih jauh, modulus elastisitas teoritis pada model kubus ditunjukkan oleh persamaan [6]

$$
\frac{E_{c}}{E_{m}}=\frac{E_{m}+\left(E_{f}-E_{m}\right) V_{f}^{3 / 2}}{E_{m}+\left(E_{f}-E_{m}\right) V_{f}^{3 / 2}\left(1-V_{f}^{3 / 2}\right)}
$$

Untuk menguji kualitas ikatan permukaan antar partikel komponen penyusun bahan komposit dipakai persamaan upper dan lower bound, yang dinyatakan dengan :

$$
E_{u}=E_{m} V_{m}+E_{f} V_{f}
$$

$E_{u}$ menyatakan modulus elastis upper bound, dan :

$$
E_{l}=\frac{E_{m} E_{f}}{V_{m} E_{f}+V_{f} E_{m}}
$$

$E_{l}$ merupakan modulus elastis lower bound, dan $E_{m}, E_{f}$ merupakan modulus elastisitas matriks, dan penguat, $V_{m}, V_{f}$ sedangkan adalah fraksi volume matriks dan fraksi volume penguat.

Nilai modulus elastisitas suatu bahan dapat digunakan untuk menguji apakah bahan tersebut membentuk komposit atau tidak. Apabila nilai modulus elastisitasnya berada di antara upper bound dan lower bound, maka dapat dikatakan bahwa bahan tersebut merupakan bahan komposit berdasarkan sifat mekaniknya.

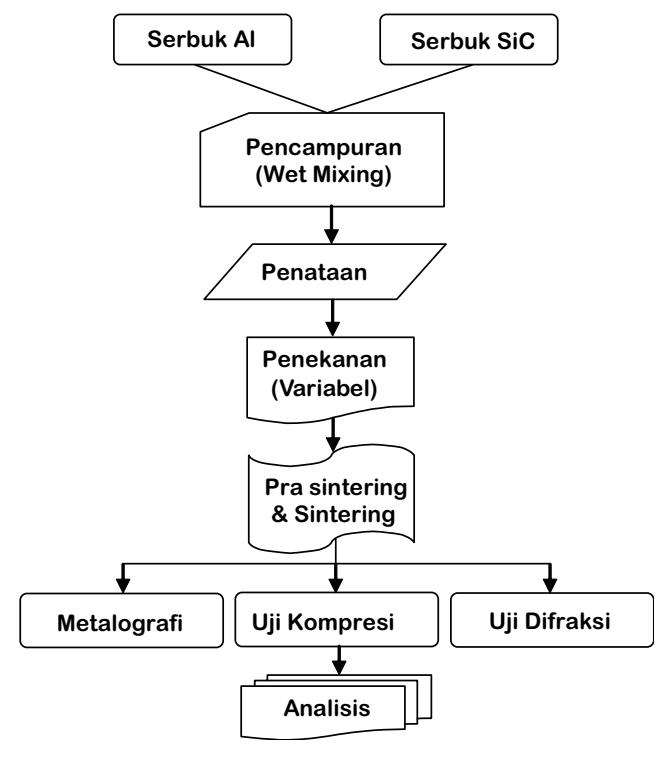

Gambar 2: Diagram alir langkah -langkah penelitian.

\section{METODOLOGI PENELITIAN}

Penelitian dilakukan dengan menggunakan bahan serbuk $\mathrm{Al}$ dan $\mathrm{SiC}$, di mana $\mathrm{Al}$ sebagai matrik dan $\mathrm{SiC}$ sebagai penguat yang dipilih dengan 3 ukuran derajat kehalusan yakni 180, 220 dan 320 mesh. Variabel yang digunakan adalah kompaksi dengan gaya kompresi sebesar 15, 20 dan 25 kilonewton $(\mathrm{kN})$. Penekanan dilakukan di lingkunan atmosfir dan dilanjutkan pra-sinter dan proses sinter dalam vakum $\left(10^{-3}\right.$ mbar). Fraksi volume penguat yang digunakan dalam eksperimen ini : $10 \%, 15 \%$ dan 20\%. Langkah - langkah penelitian selengkapnya disajikan pada diagram alir pada Gambar 2. 


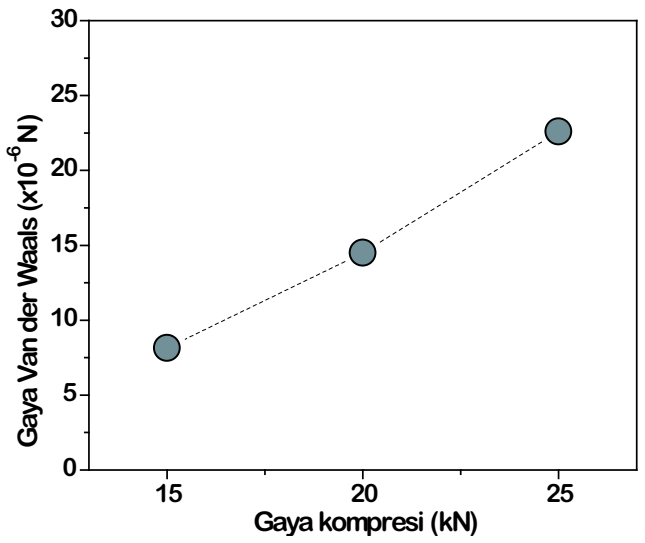

Gambar 3: Gaya Vander Waals bola-bola.

\section{HASIL DAN PEMBAHASAN}

Berdasarkan hasil perhitungan yang dilakukan dengan menganggap jarak terdekat untuk terjadinya ikatan permukaan adalah $4 \AA$, hal tersebut terjadi pada tekanan pada gaya tekan $15 \mathrm{kN}$, maka untuk model ikatan gaya Vander Waals diperoleh nilai gaya seperti tertera dalam Tabel I.

Dari Tabel I dan grafik dalam Gambar 3, terlihat bahwa semakin besar gaya tekan yang diberikan, ikatan yang terjadi juga semakin meningkat. Hal tersebut disebabkan oleh adanya hubungan linier antara besarnya gaya ikat dan jarak antar partikel serbuk seperti ditunjukkan oleh persamaan (2). Bentuk ikatan bola-bola, bidang-bola dan bidang-bidang diasumsikan menghasilkan gaya di atas kekuatan luluh matriks (Al) dan di bawah kekuatan luluh penguat (SiC). Dengan demikian, matriks akan mengalami deformasi plastis sedangkan bahan penguat masih pada daerah elastis, dan memungkinkan terjadinya ikatan antar partikel pada matriks - matriks, matriks - penguat dan penguat - penguat. Meskipun pada penelitian ini digunakan gaya di atas kekuatan luluh partikel matriks, tetapi akibat gaya gesek yang terjadi antara partikel - partikel serbuk atau partikel serbuk dengan dinding cetakan menyebabkan gaya yang diberikan menjadi lebih kecil daripada gaya yang sebenarnya. Hal tersebut mengakibatkan partikel matrik tidak mengalami deformasi plastik tetapi masih berada pada daerah elastik sehingga terjadi pemulihan (recovery) elastisitas ke dalam bentuk bola. Untuk model bidang-bola gaya Van der Waals, nilai tegan-

TABEL I: Gaya Van der Waals model bola-bola

\begin{tabular}{ccc}
\hline \hline No. & Gaya Kompresi(kN) & Gaya Van der Waals (N) \\
\hline 1 & 15 & $8,15 \times 10^{-6}$ \\
2 & 20 & $14,50 \times 10^{-6}$ \\
3 & 25 & $22,60 \times 10^{-6}$ \\
\hline
\end{tabular}

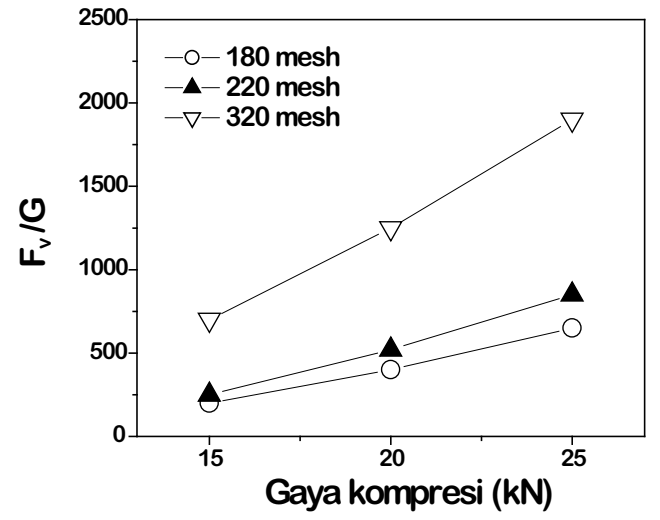

Gambar 4: Variabel gaya kompresi terhadap gaya Vander Waals bola-bidang.

TABEL II: Modulus Young komposit Al-SiC model tabung dan kubus

\begin{tabular}{cccc}
\hline \hline No. & Fraksi & Modulus \\
Volume & $\begin{array}{c}\text { Young } \\
\text { Penguat-SiC }\end{array}$ & $\begin{array}{c}\text { Modulus } \\
\text { Young } \\
\text { Model Tabung } \\
\left(\mathrm{N} / \mathrm{m}^{2}\right)\end{array}$ & $\begin{array}{c}\text { Model Kubus } \\
\left(\mathrm{N} / \mathrm{m}^{2}\right)\end{array}$ \\
\hline 1 & $(\%)$ & $77,6 \times 10^{9}$ & $94,48 \times 10^{9}$ \\
2 & 10 & $81,9 \times 10^{9}$ & $104,70 \times 10^{9}$ \\
3 & 15 & $93,3 \times 10^{9}$ & $114,80 \times 10^{9}$ \\
\hline \hline
\end{tabular}

gan yang diberikan terletak di antara kekuatan luluh matrik dan penguat sehingga diperoleh grafik seperti dalam Gambar 4.

Untuk memprediksi besarnya modulus elastisitas Young komposit secara teoritik untuk bahan komposit AlSiC dengan persaman Hal Pin Tsi [6] diperoleh hasil yang diberikan pada Tabel II. Selanjutnya, untuk menguji kualitas ikatan permukaan, dilakukan perhitungan limit upper dan lower bound, sehingga akibat variabel kompaksi dapat dinyatakan bahan tersebut menjadi komposit atau aglomerit.

Gambar 5 menunjukkan bahwa dengan adanya kompresi yang semakin tinggi, ternyata besar modulus Young terletak di luar batas upper dan lower bound. Hal tersebut menunjukkan bahwa pada partikel-partikel un-

TABEL III: Besar modulus Young Al-SiC berdasarkan data pengukuran

\begin{tabular}{ccc}
\hline \hline No. & Gaya Kompresi & Modulus Young \\
& $(\mathrm{kN})$ & $\mathrm{Al}-\mathrm{SiC}\left(\frac{V}{V_{0}}=20 \%\right)\left(\mathrm{N} / \mathrm{m}^{2}\right)$ \\
\hline 1 & 15 & 120 \\
2 & 20 & 90 \\
3 & 25 & 73 \\
\hline \hline
\end{tabular}




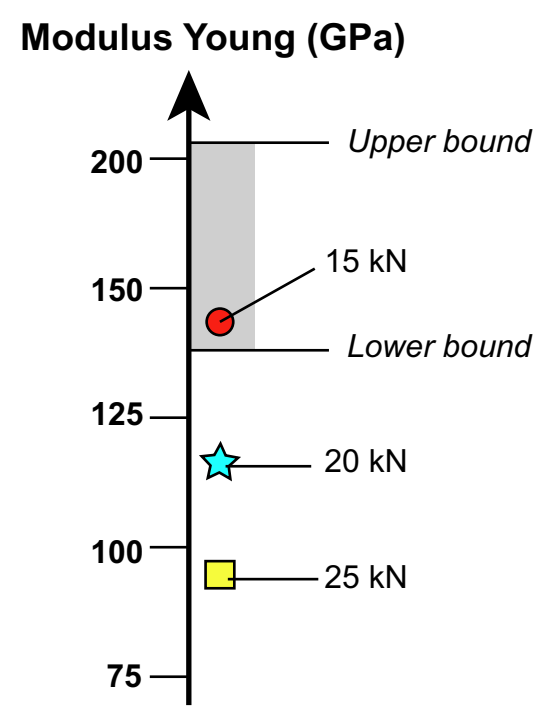

Gambar 5: Limit upper dan lower bound dan hasil eksperimen.

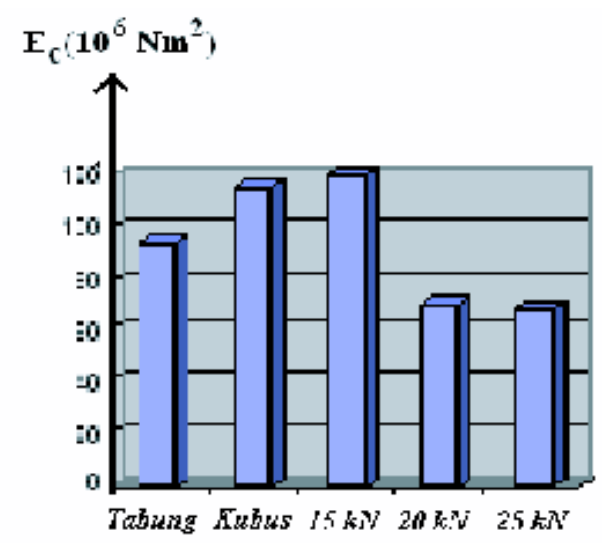

Gambar 6: Modulus Young Komposit Al-SiC dari perhitungan teoritis dan dan hasil eksperimen.

tuk kompresi tinggi tidak terjadi ikatan permukaan dengan baik (aglomerasi). Terjadinya proses tersebut karena tekanan tinggi menginduksi penjebakan (trapping) gas atau pelumas selama proses kompaksi, sehingga pada saat proses sinter dalam vakum peristiwa pelepasan gas ( $d e-$ gassing) tidak dapat terjadi. Sebagai akibatnya, komposit tidak mengalami penyusutan (shrinkage) tetapi malah terjadi pemekaran (bloating). Pengembangan dimensi menyebabkan bahan menjadi getas dan mengakibatkan kegagalan pembuatan bahan komposit. Pada Gambar 6 ditunjukkan bahwa gaya tekan $15 \mathrm{kN}$ mendekati harga teoritis dibandingkan dengan gaya tekan 20 dan $25 \mathrm{kN}$.

Untuk mengetahui lebih lanjut gambaran struktur mikro dari bahan komposit yang dihasilkan, pada Gambar 7 diberikan hasil foto dengan mikroskup optik (metalografi) permukaan sampel yang disiapkan dengan kompaksi yang bervariasi. Teramati retak-mikro (micro cracking) pada permukaan sampel hasil fabrikasi dengan gaya kompresi terbesar (Gambar 7d) yang digunakan dalam penelitian ini.
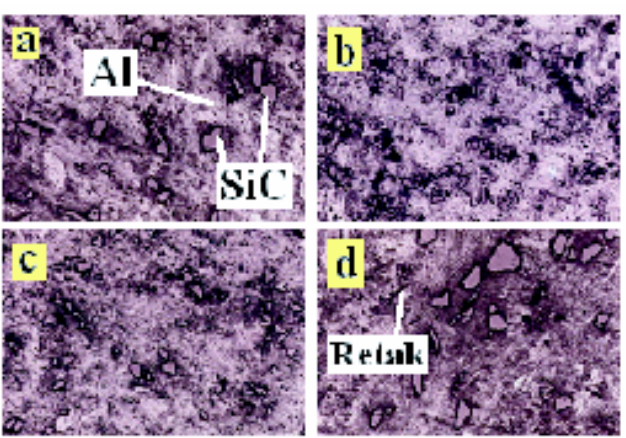

Gambar 7: Struktur mikro bahan komposit Al-SiC hasil fabrikasi dengan kompaksi : (a,c)15 kN, (b) $20 \mathrm{kN}$, dan (d) $25 \mathrm{kN}$.

\section{KESIMPULAN}

Bahan komposit yang tersusun dari serbuk Al sebagai matriks dan serbuk $\mathrm{SiC}$ sebagai penguat dapat dibentuk dengan baik, yang ditunjukkan oleh terjadinya ikatan permukaan antar kedua jenis partikel yang bersangkutan. Kompaksi dengan tekanan di atas kekuatan luluh Al menyebabkan penurunan kualitas ikatan permukaan, sebagai akibat terjebaknya gas dan bahan pelumas yang digunakan dalam proses fabrikasi. Gaya kompresi sebesar $15 \mathrm{kN}$ menghasilkan kualitas ikatan permukaan yang terbaik, terbukti dengan nilai modulus Young yang terletak di antara batas upper dan lower bound. Model partikel penguat dengan geometri tabung dan kubus pada komposit isotropik dapat digunakan untuk memprediksi nilai modulus elastisitas komposit dan hasilnya nampak mendekati hasil eksperimen.
[1] F. V. Lenel, Powder Metallurgy Principles and Applications, Metal Powder Industries Federation, New Jersey, 1980.

[2] M. Zainuri, Pengaruh variabel fraksi Volume SiC terhadap modulus Young komposit Al-SiC, Tesis Magister, Program Material Sience, Universitas Indonesia, Jakarta, 1994.

[3] M. Zainuri, Y. Nirwanawati, E. Kurniawan, Triwikantoro, 
dan Darminto, Modulus elastisitas dan karakteristik antarmuka matriks - pengisi pada bahan komposit isotropik Al-SiC, Prosiding Simposium Fisika Nasional XX, Himpunan Fisika Indonesia, Pekan Baru, 25-26 Agustus 2004 (in press).

[4] K. Okuyang, Adhesion force of single particle, Powder Tech- nology Handbook, Marcel Dekker Inc. New York, 1990.

[5] R. Tadmor, J. Phys. : Condens. Matter. 13, L195 (2001).

[6] B. D. Agarwal, Analysis and Performance of fiber Composite, John Wiley \& Sons Inc., New York, 1980. 